\title{
Ahlat - Malazgirt Yapı Taşlarının Isıl ve Mekanik Özellikleri
}

\author{
Ayşe BíçER* \\ Kimya Mühendisliği Bölümü, Mühendislik Fakültesi, Fırat Üniversitesi, Elazığ, Türkiye \\ abicer@firat.edu.tr
}

(Geliş/Received: 01/12/2018;

Kabul/Accepted: 23/05/2019)

\begin{abstract}
Öz: Bu çalışmada, Süphan Dağı'ndan çıkan volkanik ürünlerin soğuyup katılaşmasıyla oluşmuş Ahlat ve Malazgirt taşlarının bazı 1sıl ve mekanik özellikleri araștırılmıștır. Ahlat tașı, Bitlis ilinin Ahlat ve Malazgirt tașı, Muș ilinin Malazgirt ilçe merkezi ve çevresinde yaygın bir şekilde bina yapı elemanı olarak kullanılmakta ve halk arasında işleme kolaylığ ve 1 sıl özellikleri açısından övgü ile sözü edilmektedir. Amaç, bölgede çok kullanılan taşların, bina yapı elemanı olarak gerçekte ne tür özelliklere sahip olduğunu belirlemektir. Taşların özelliklerini belirlemek üzere, her taş için iki ayrı taş ocağından numuneler alındı. Numunelere uygulanan 1sıl ve mekanik testler sonucu, taşların bazı özellikleri belirlenerek benzeri yapı malzemeleri ile karşılaştırılmıştır. Bu çalışma sonucunda, taşların, kolayca işlenebilmesi, rezervlerinin zengin, maliyetlerinin düşük ve 1sıl konfor yönünden birçok yapı elemanına kıyasla daha iyi olması nedeniyle tercih edildiği saptanmıştır.
\end{abstract}

Anahtar kelimeler: Andezit tüf, ignimbirit, Ahlat taşı, Malazgirt taşı, yapı malzemesi.

\section{Thermal and Mechanical Properties of the Building Stones from Ahlat and Malazgirt}

\begin{abstract}
In this study, certain thermal and mechanical properties of the Ahlat and Malazgirt stones formed by the cooling and solidification of volcanic products from Suphan Mountain are examined.. Ahlat and Malazgirt stones from Bitlis province are widely used as a building material in Malazgirt district's central area of Muş province, gaining an immense reputation in the community thanks to its easy of handling and thermal properties. The objective here is to determine the kind of properties these stones have as a building material. With this objective, stone samples from two separate sources were taken. Thermal and mechanical tests carried out on the samples were compared with similar building materials by determining certain properties of the resultant stones. With this study, it is inferred that these stones are preferred thanks to its ease of handling, enriched reserves, low-costs, as well as bearing better properties compared to a number of building materials in terms of thermal comfort.
\end{abstract}

Key words: Andesite tuff, ignimbrite , Ahlat stone, Malazgirt stone, building material

\section{Giriş}

Bazı volkanlardan çıkan volkanik malzemenin soğuyup katılaşmasıyla piroklastik bir kayaç türü olan andezitik tüfler oluşur. Doğu Anadolu Bölgesi'nde mineralojik bileşimi değişiklik gösteren 15 'e yakın andezitik tüf bulunmaktadır. Nemrut dağı, Süphan, dağı, Dumanlı (Erzurum), Küçük ve Büyük Ağrı Dağlan, Çat (Erzurum), Hamur (Ağrı), Kars dağlanın andezit tüfleri örnek olarak sayılabilir [1]. Bu tüflerin bir kısmı, "Kızgın, halde akan", "kaynaklaşmış tüf” anlamına gelen ignimbirittir. İgnimbiritler genel olarak asit bileşimli magmaların patlaması sonucu oluşmuş piroklastik kayaçlardır. Yoğunlukları düşük, dayanımları yüksek, kolay şekil alabildikleri ve mükemmel yalıtım malzemesi özelliğine sahip oldukları için Dünya'nın birçok yerinde olduğu gibi ülkemizde de yapıtaşı olarak kullanılmaktadır. Taşı oluşturan başlıca mineraller plajiyoklaz (oligoklaz, andezin, nadiren labrador), piroksen (ojit, klinoenstatit) ve opak mineraller (manyetit, ilmenit) olup daha az oranda da kuvars, biyotit ve amfibol bulundurabilir. Taşların kırmızı, siyah, gri, beyaz, kül rengi türleri mevcuttur. Taşlar yapı olarak bünyesinde mikro gözeneklere sahip olup hem hafif hem de yalıtım özelliğine sahiptir. Dolayısıyla 1sı ve ses yalıtımı nedeniyle geçmişte olduğu gibi günümüzde de bu taşlar tekrar büyük önem kazanmıştır. Son yıllarda gerek enerji maliyetleri ve gerekse inşaat malzemelerindeki fiyat artışları her bir yörenin jeolojik yapısına bağlı olarak doğal taşların taşıyıcı ve dolgu elemanı olarak kullanılmasını gündeme getirebilir. Taşlar ocaklardan çıkarıldığı zaman, bünyesinde bulunan nem nedeniyle kesilmesi yontulması işlenmesi oldukça kolaydır. Zaman içerisinde nem bünyeden atılarak taşlar sertleşmekte ve dayanım kazanılmaktadır.

\footnotetext{
* Sorumlu yazar: abicer@ firat.edu.tr. Yazarın ORCID Numarası: 000000034.514.564
} 
Yapı malzemesi olarak kullanılabilirliği araştırılan Ahlat ve Malazgirt taşları Süphan Dağı'nın püskürttüğü piroklastik malzemenin ani şekilde soğuması sonucu oluşmuş taşlardır. Taşlar, ocaktan yeni çıkartıldığında ahşap gibi testere ile kolayca kesilebilmekte, matkap ile delinebilmekte, sert cisimlerle yontulabilmekte ve hatta çivi çakılabilmektedir Taşların bu özellikleri ile yörede inşa edilen binalarda yapı malzemesi olarak itibar görmesini sağlamıştır.

Taşlarla ilgili birçok çalışmalar yapılmış olup bunların bir kısmı özetle; Gevrek ve Kazancı (1991), ignimbrit: oluşumu üzerine çalışmıştır. Bakış ve arkadaşları (2014), Ahlat Taşının inşaat sektöründe kullanımını, Akın ve arkadaşları (2014) Ahlat Taşı'nın atmosferik etkiler altındaki duyarlılığı konusunu araştırmıştır. Kazancı ve Gürbüz (2014), Türkiye Doğal Taşları'nın jeolojik oluşumları ile ilgili çalışmışlar. Pivko (2003), Dünyadaki taşların tarihsel oluşumu ile ilgili çalışma yapmıştır. Dinçer ve arkadaşları (2012), ignimbiritlerin kapiler su emme potansiyellerinin değerlendirilmesi ile ilgili çalışma yapmış ve Ahlat Taşı örneği verilmiștir. Akılll (1987), taş eserlerin tahribatına neden olan etkenleri araştırmıştır. Gürdal (1982), anıtlarda ve yapılarda kullanılmış doğal taşların bozulmaları nedenleri ve korunmaları konusunu araştırma yapmıştır.

$\mathrm{Bu}$ çalışmada Bitlis ili Ahlat ilçesinde bulunan Ahlat taşı ile Muş ilinin Malazgirt ilçesinde bulunan Malazgirt taşlarının bazı özellikleri araştırılmıştır. Taşlar, uzun yıllar bölge yapılarında taşıyıcı yapı elemanı olarak kullanılmış ve halk arasında çok muteber bir yapı elemanı olarak kabul görmüștür. Bu itibar gerçekten iyi bir malzeme olmasından $\mathrm{m} ı$ yoksa teminindeki kolaylıktan $\mathrm{m}$ kaynaklandığı belirli değildir. Bu çalışma konuya 1şık tutmak amacıyla yapılmıştır.

\section{Materyal ve Yöntem}

\subsection{Malzemelerin özelliği}

Ahlat Taşı: Ahlat, Bitlis ilinin $60 \mathrm{~km}$ uzaklığında ve kuzey doğusunda, Süphan ve Nemrut dağları arasında, Van Gölü’ne bakan eğimli platolar üzerinde kurulmuş bir Bitlis ilçesidir (Şekil 1). Taşlar Ahlat kazasına üç km uzaklıkta bulunan ocaklardan çıkarılmaktadır. Ahlat taşı, Süphan Dağı volkanik malzemenin ani şekilde soğuması sonucu oluştuğundan kalıp kalıptır. Çünkü volkanik malzemeler katman katman akmıştır [1]. Taşların çeşitli renkte olması cephe süslemesinde bolca kullanmasına neden olmuştur [7]. Taş yapısı itibariyle volkanik olduğundan hafiftir. Fakat buna karşılık çok dayanıklıdır. Öyle ki oksijen kaynağı taşı eritememektedir [1]. Bu özelliklerinden dolayı yapılarda yoğun bir şekilde kullanılmaktadır. Büyük rezervlere sahip olan taşın maliyeti düşüktür. Bu taşlar Selçuklular döneminde yörede birçok tarihi eserlerde kullanılmıştır. Günümüzde Ahlat ilçesinde bulunan Büyük Selçuklu Oteli bu taşlardan yapılmıştır. Taşlar yörede cami minarelerinin yapımında da kullanılmaktadır. Taşların ocaktan çıkarılışı ve şekillendirilmesi oldukça kolaydır.

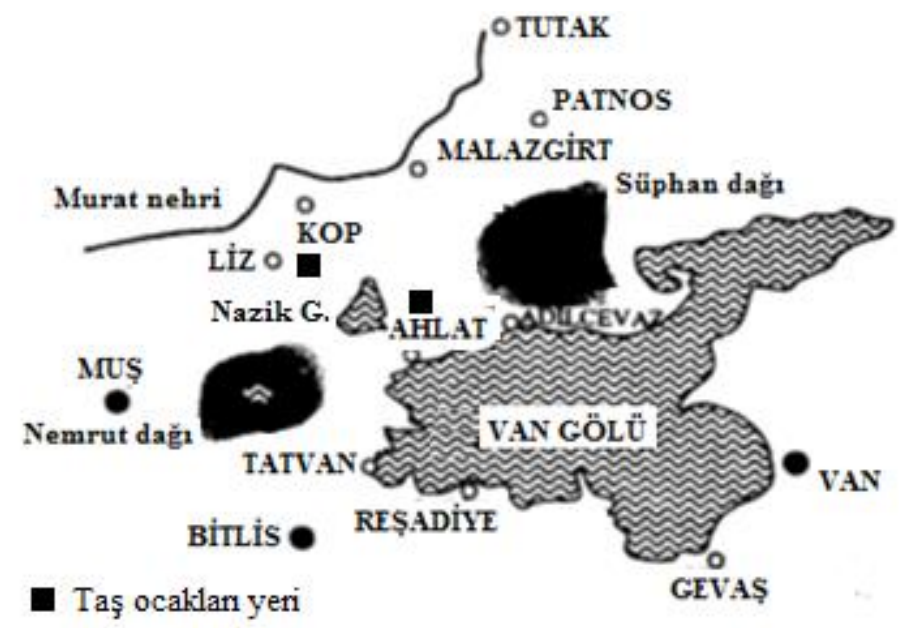

Şekil 1. Ahlat ve Malazgirt ilçelerini gösteren harita.

Malazgirt Taşı: Muş ilinin Malazgirt kazasına bağlı Liz köyünde bulunan taş ocaklarından "Liz Taşı" adıyla iki ayrı taş olarak çıkarılmaktadır. Bu taşların, biri kırmızı diğeri siyah renklidir. Liz taşları çok uzun yıllardan beri kullanılmaktadır. Buna örnek Malazgirt kazasında bulunan Malazgirt Kalesi siyah Liz taşından yapılmıștır. Bu kalenin hala ayakta olması taşın dayanaklığının bir göstergesidir. Yörede Liz taşı ile yapılan 
evlere taş evler ismi verilmektedir. Bu taşların maliyeti oldukça ucuzdur. Taşları ocaktan çıkarılması kolay olup nem oranı yüksek, mukavemet değeri düşük ve işlenmesi kolaydır [6].

Taşların yapılan kimyasal analiz sonuçları Tablo 1'de gösterildiği gibi topluca verilmiştir.

Tablo 1. Taşların kimyasal analiz sonuçları.

\begin{tabular}{|l|c|c|c|c|c|c|c|}
\hline \multicolumn{1}{|c|}{ Bileşen } & $\mathrm{SiO}_{2}$ & $\mathrm{Al}_{2} \mathrm{O}_{3}$ & $\mathrm{Fe}_{2} \mathrm{O}_{3}$ & $\mathrm{CaO}$ & $\mathrm{SO}_{3}$ & $\begin{array}{c}\text { Kızdırma } \\
\text { Tayb1 ad1 }\end{array}$ & $\begin{array}{c}\text { Tayin } \\
\text { edilemeyen }\end{array}$ \\
\hline Malazgirt T. ocak 1 & 63.73 & 14.97 & 4.45 & 3.66 & - & 3.40 & 9.79 \\
\hline Malazgirt T. ocak 2 & 64.13 & 16.55 & 4.50 & 3.66 & 0.50 & 2.90 & 7.76 \\
\hline Ahlat taş1 ocak 1 & 62.73 & 16.60 & 4.50 & 3.23 & 1.44 & 2.53 & 8.97 \\
\hline Ahlat taşı ocak 2 & 63.80 & 16.50 & 4.45 & 3.55 & 1.55 & 3.40 & 6.75 \\
\hline
\end{tabular}

Taşların kırmızı, siyah, gri, beyaz gibi renkleri mevcuttur (Şekil 2). Taşlar günümüzde bölgede yapı malzemesi olarak kullanıldığı gibi Anadolu'nun birçok yöresine de gönderilmektedir.

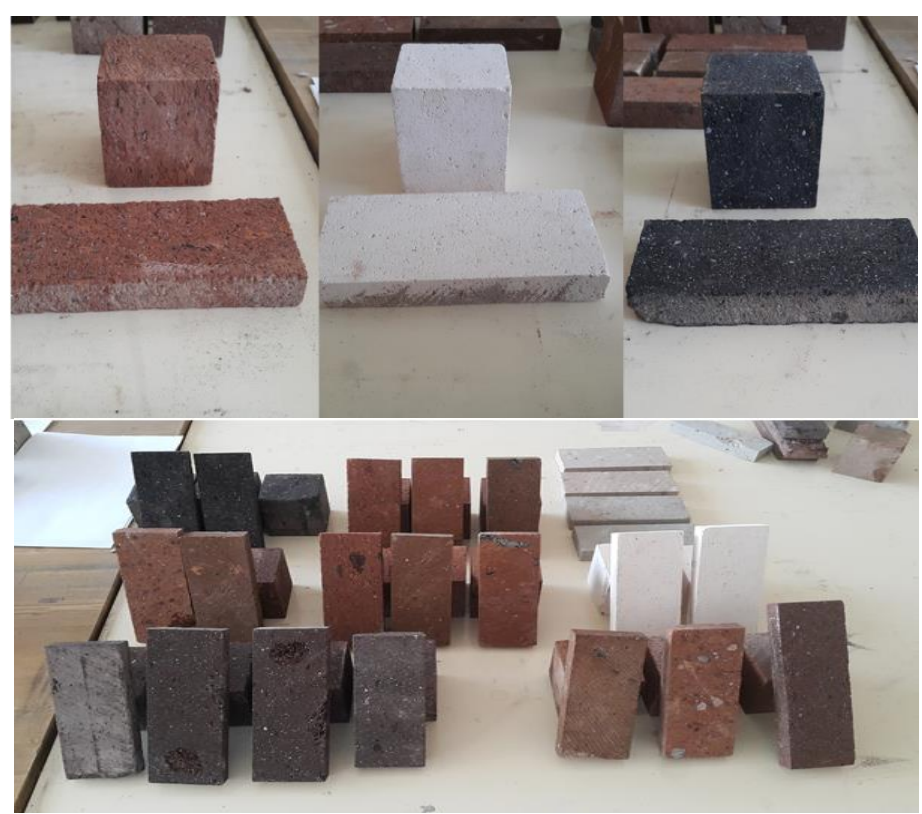

Şekil 2. Ahlat ve Malazgirt taşlarının farklı renkteki örnekleri.

\section{2. Örneklerin hazırlanması}

Taşların her biri yörelerinde iki farklı ocaktan alınarak ocak numaraları 1 ve 2 rakamları ile taş isimlerine eklenmiştir. Ocaklardan alınan taşlardan 1sıl deneyler için 150x60×20 mm ölçülerinde, basınç ve aşınma deneyleri için ise 100x100x100 mm ebatlarında numuneler hazırlanmışıtır (Şekil 2). Taşlar ocaklardan çıkarıldığı zaman bünyesindeki nem nedeniyle, kesilmesi istenilen şekillerin verilmesi kolaydır. Hazırlanan numuneler oda sıcaklığında, 28 günlük doğal kurumaya bırakıldıktan sonra herhangi bir işlem yapılmadan ölçümler yapılmıştır.

\section{3. Ölçme yöntemleri}

\subsubsection{Isıl iletkenlik}

Geçici rejimde ölçme yapan ve sıcak tel (Hot Wire) yöntemi ile çalışan "Isomet 2104" marka cihazı ile ölçümler yapılmıştır [10, 11] (Şekil 3). DIN 51046 normuna göre ölçüm yapan bu cihazla, Isı iletim katsayısı, 22-25 ${ }^{\circ} \mathrm{C}$ oda sıcaklığında ve her numune üzerinde 5 farklı noktadan ölçümler yapılmış ve bu 
ölçümlerden birbirine uyumlu olan 3 değerin aritmetik ortalamaları alınmıştır. Cihaz ısı iletim katsayısını 0.02-6 $\mathrm{W} / \mathrm{mK}$ aralığında $\% 5$ hassasiyetle vermektedir. Tablo 2'de görülen bazı yapı malzemelerin yoğunluk ve 1 sıl iletkenlik değerleri Şekil 4'de gösterilen taşların yoğunluk ve isıl iletkenlik değerleri ile karşılaştırma yapmak üzere topluca verilmiştir.

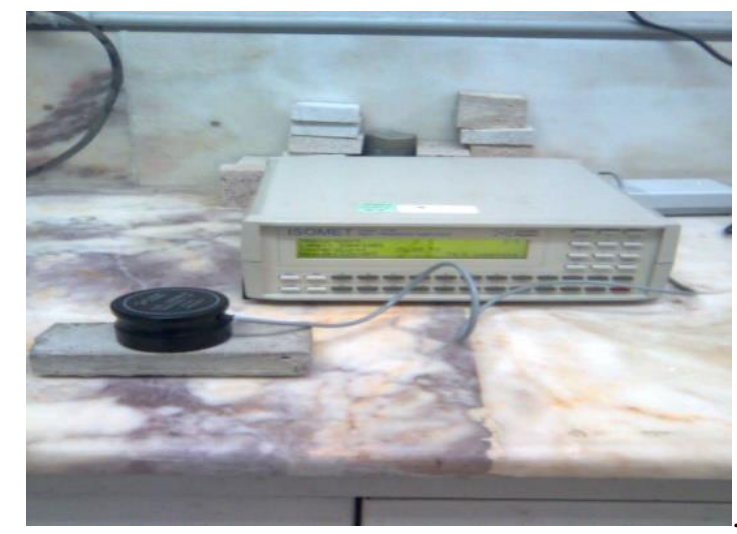

Şekil 3. Isomet 2104 ölçme aleti.

Tablo 2. Bazı yapı malzemelerin yoğunluk ve 1sıl iletkenlik değerleri [12.13.14].

\begin{tabular}{|c|c|c|}
\hline Malzeme & $\begin{array}{c}\text { Yoğunluk } \\
\left(\mathrm{g} / \mathrm{cm}^{3}\right)\end{array}$ & $\begin{array}{c}\text { Is1l iletkenlik } \\
(\mathrm{W} / \mathrm{mK})\end{array}$ \\
\hline Beton & 1906 & 0.814 \\
\hline Granit & 2643 & $1.73-3.98$ \\
\hline Kalker & 2483 & 1.16 \\
\hline Kum taş1 & $2163-2307$ & $1.63-2.08$ \\
\hline Mermer & $2499-2707$ & 2.77 \\
\hline Tuğla & 1602 & 0.692 \\
\hline Seramik toprak & 1.077 & 0.214 \\
\hline Ytong & 0.800 & 0.383 \\
\hline
\end{tabular}

\subsubsection{Basınç, çekme ve aşınma deneyleri}

Numuneler üzerinde TS 699 standardına uygun dayanım deneyleri yapılmıştır [15]. Numunelere uygulanan basınç Ele International marka, $3000 \mathrm{kN}$ yükleme kapasiteli, dijital kumanda panelli, yükleme hızı ayarlanabilen ve tek eksende kuvvet uygulayabilen cihazla yapılmıștır. Basınç dayanımı sonuçları, TS 500' e göre aşağıdaki Denklem 1" ile çekme dayanımına dönüştürülmüştür [13]. Sonuçlar Şekil 4'de topluca verilmiştir.

$$
f_{c t k}=0.35 \sqrt{f_{c k}}
$$

Burada;

$\mathrm{f}_{\text {ck }}$ : basınç dayanımı $(\mathrm{MPa})$ ve $\mathrm{f}_{\text {ctk: }}$ : çekme dayanımı $(\mathrm{MPa})^{\prime}$ dır.

Yapılan sürtünmeden aşınma deneylerinde (Böhme), 88 devir için hacim cinsinden aşınma kaybı sonuçları Şekil 4'de topluca verilmiş̧ir.

\subsubsection{Su emme deneyi}

$\mathrm{Bu}$ deneyin amacı, su ile direk temasta kalan yapı malzemelerinin donma sürecinde, bünyesinde teșekkül eden buz kristallerinin genleşme imkânı bulabileceği bir kuru hacmin varlığının araştııılmasıdır. Bu özellik malzemede donmaya karşı güvence sağlamaktadır. Her numunenin kuru ağırlığı $\left(\mathrm{W}_{\mathrm{k}}\right)$ tespit edilmiştir. Daha 
sonra numunelerin konduğu bir su kabında su seviyesi kademeli olarak yükseltilmiş ve numunelerin tamamı su içinde kalacak şekilde kaba su ilave edilmiştir. Numuneler 48 saat su içinde bekletildikten sonra sudan çıkarılıp silinerek, su emdirilmiş ağırlıkları $\left(\mathrm{W}_{\mathrm{d}}\right)$ bulunmuş ve "Denklem 2" ile su emme oranı hesaplanmıştır [11]. Sonuçlar Şekil 4'de verilmiştir.

Su emme oran1 $=\frac{W_{\mathrm{d}}-\mathrm{W}_{\mathrm{k}}}{\mathrm{W}_{\mathrm{k}}}-100$

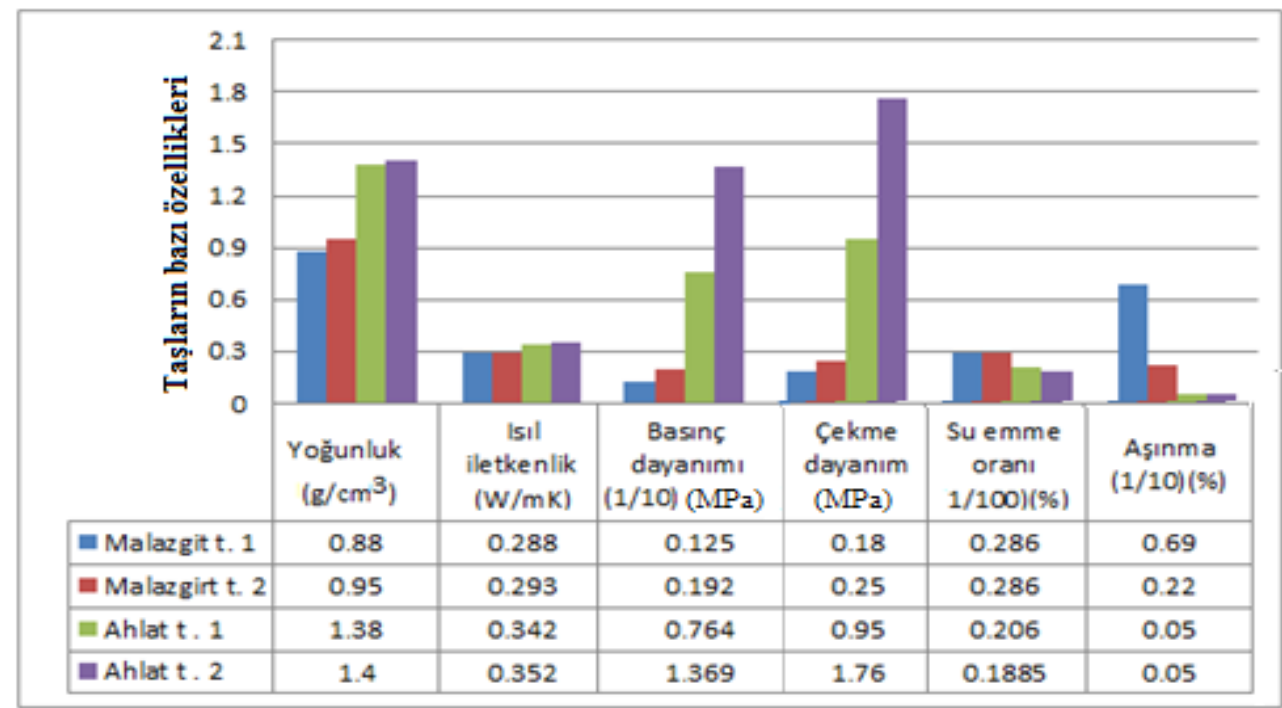

Şekil 4. Taşların ısıl ve mekanik özellikleri.

\subsubsection{Kuruma oranı testi}

Kuruma oranı deneyinde amaç, numunelerin teneffüs kabiliyeti mevcudiyetinin araştırılmasıdır [11, 13]. 48 saat su kabı içerisinde bekletilen numuneler sudan çıkarılıp sslak bir bezle silindikten sonra $22{ }^{\circ} \mathrm{C}$ oda sıcaklığında doğal kurumaya bırakılmıştır. 48 saatlik kuruma süreci sonunda kuruma oranları, "Denklem 3" ile hesaplanmıştır Sonuçlar Şekil 6'da zamana karşı grafik halinde gösterilmiştir. Kuruma malzeme yüzeyinden buharlaşma yolu ile olduğundan, burada malzeme derinliğinden yüzeye kılcal kanallar vasıtasıyla suyun hareketi söz konusudur. Yani buhar geçirgenlik direnci vasıtasıyla rutubet bünyeden atılarak kurumaktadır.

Kuruma oran1 $=\frac{\mathrm{W}_{\mathrm{d}}-\mathrm{W}_{\mathrm{k}}}{\mathrm{W}_{\mathrm{d}}}-100$

\subsubsection{Yoğunluk testi}

Numunelerin kuru ağırlıkları \%1 hassasiyetle ölçme yapan terazide ölçülmüş ve numune hacimleri belirlenerek yoğunluklar hesap edilmiştir. Sonuçlar Şekil 4'de gösterilmiştir.

\section{Sonuçlar ve Tartışma}

Hazırlanan numunelere uygulanan testler sonucu; taşlar yapısı itibariyle volkanik olduğundan oldukça hafiftir. Gerek sürekli ve gerekse zamana bağlı rejimde Malazgirt taşı $0.29 \mathrm{~W} / \mathrm{mK}$ ortalama 1sı iletim katsayısı ile diğer benzeri beton, granit, kalker, mermer ve adi tuğlaya göre daha iyi durumdadır (Tablo 2 ve Şekil 4). Bu taşlar ile yapılan binalar, kışın sıcak ve yazın da serin olmakta gece ile gündüz ve mevsimler arasında meydana gelen sicaklık değişiminden çok az etkilenmektedir. 
Malazgirt taşının avantajılı ısıl özelliklerinin yanı sıra ortalama 1.5 MPa basınç ve 0.2 MPa çekme dayanımı göz önüne alındığında düşük değerlere sahiptir. Ancak briket, tuğla, ytong [6] gibi yapay malzemelerle eşdeğer dayanıma sahiptirler.

Ahlat 1 ve 2 taşları $0.35 \mathrm{~W} / \mathrm{mK}$ ortalama 1sıl iletkenlik değeri ile Malazgirt taşları gibi bir çok benzeri malzemelerden daha iyi durumdadır. Basınç ve çekme dayanım ile aşınma değerleri için Malazgirt taşlarından daha yüksek dayanım değerlerine sahiptir. Bu nedenle Ahlat taşı binalarda bölme elemanı olarak kullanımı yanında yük taşıyıcı elemanı olarak da kullanılabilmektedir.

Taşların, \%0.5-6.9 luk aşınma kaybı ile merdiven, parke gibi fazla aşınmaya maruz yapı elemanı olarak kullanılamayacağını göstermektedir.

Taşların su emme oranının \%30'dan küçük olması taşların nemli ortamlarda kullanılabileceğini gösterir [7]. Su emme deneyinde numunelerin zamana göre ağırlık değişimi Şekil 4 de gösterilmiştir. Şekil (5) incelenmesi halinde, taşların az da olsa teneffüs kabiliyetine sahip olduğunu göstermektedir.

Taş numuneleri üzerinde yapılan hacim ölçüleri ile hassas terazide yapılan ağırlık ölçümleri kullanılarak yapılan hesaplardan, yoğunluğun ortalama Malazgirt taşı 1'in $880 \mathrm{Kg} / \mathrm{m}^{3}$ ve Malazgirt taşı 2 taşının $950 \mathrm{Kg} / \mathrm{m}^{3}$, Ahlat taşı 1'in $1400 \mathrm{Kg} / \mathrm{m}^{3}$ ve Ahlat taşı 2'nin ise $1380 \mathrm{Kg} / \mathrm{m}^{3}$ olarak belirlenmiştir.

Taşların birçok yapı elemanına kıyasla kolayca işlenebilmesi, elektrik ve su tesisatı kanallarının açılması, delinebilmesi, kesilebilmesi, yontulabilmesi, çivi ve vida kullanılmasına izin vermesi büyük avantajdır.

Taşların maliyetlerinin düşük, temininin kolay, rezervlerinin zengin, 1sıl özelliklerinin iyi olması nedeniyle yapılarda bölme ve yük taşıyıcı eleman olarak tuğla veya briket yerine kullanılması tercih nedeni olmaktadır

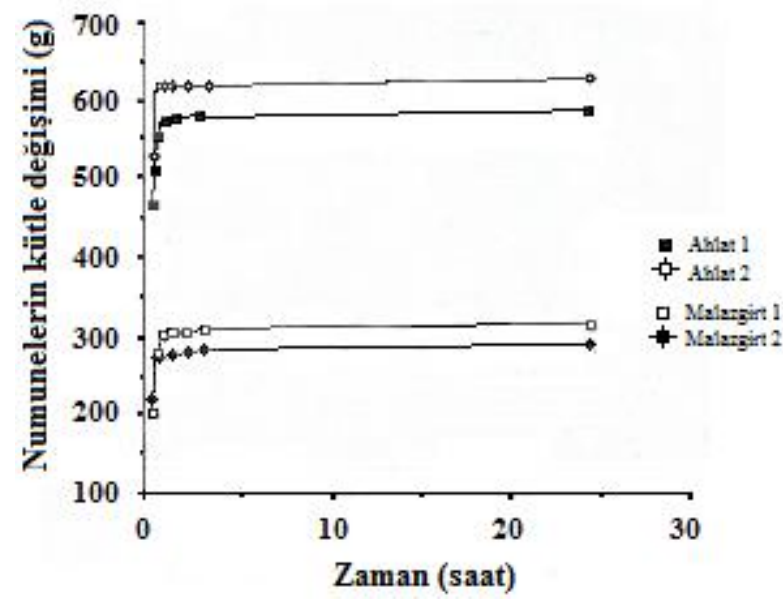

Şekil 5. Su emme deneyinde taşların zamana göre kütle değişimi

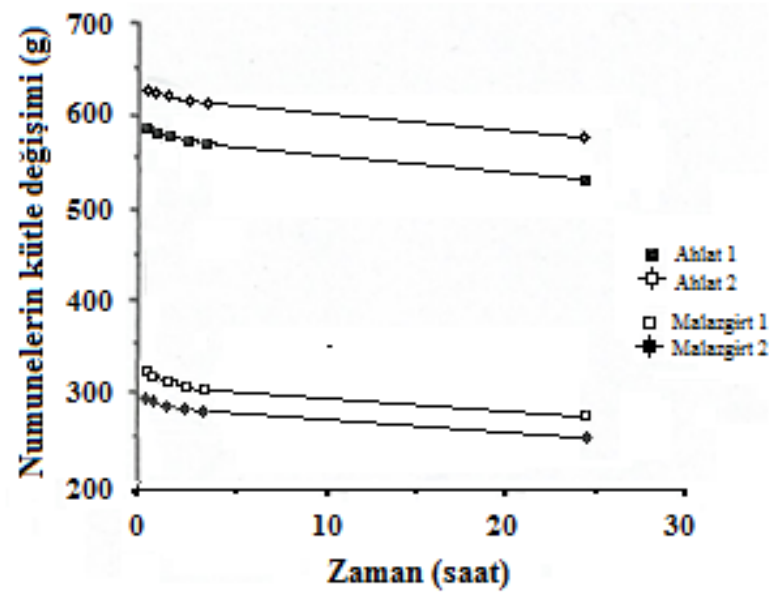

Şekil 6. Kuruma deneyinde taşların zamana göre kütle değişimi 
Ayşe BİÇER

\section{Sonuçlar}

Yöre halkı tarafından muteber bir yapı malzemesi olarak kabul edilip kullanılan Ahlat ve Malazgirt taşları için yapılan araştırma ve testler sonucu;

1- Bu taşların rezervleri zengin olup, uzun yıllar kullanılmaya müsaittir.

2- Taşların temini kolay ve maliyetleri düşüktür.

3- Malazgirt taşının 0.288-0.293 W/mK ısı iletim katsayısı, 1.25-192 MPa basınç gerilmesi ve 2.2-6.9\% aşınma değerleri ile bölge yapılarında; 1 sıl konfor için, dekoratif amaçlı ve bölme elemanı olarak kullanıldığı.

4- Ahlat taşı, $0.342-0.352 \mathrm{~W} / \mathrm{mK}$ 1sı iletim katsayısı, 7.64-13.69 MPa basınç gerilmesi ve $0.5 \%$ aşınma değerleri ile gerek 1sıl konfor için, gerekse bölme ve yük taşıyıcı eleman olarak kullanılabilir özellikte olduğu belirlenmiştir

Taşlar, bu çalışmada, belirlenen ısıl ve mekanik özellikler ile yapı malzemesi olarak bölge ve civar illerde tercih edilmesine neden olmuştur.

\section{Kaynaklar}

[1] Boran, A. Van Gölü çevresindeki tek kubbeli camilerin Türk sanatındaki yeri, Yüzüncü Yıl Üniversitesi Sosyal Bilimler Enstitüsü Yüksek Lisans Tezi, 1994.

[2] Gevrek, A. İ. ve Kazanc1, N. İgnimbrit: oluşumu ve özellikleri, Jeoloji Mühendisliği Dergisi, Ankara 1991.38; $39-42$.

[3] Bakış A, Işık E, Hattatoğlu F. Akıllı A. Jeolojik miras nitelikli Ahlat Taşı'nın inşaat sektöründe kullanımı, III. Uluslararası Ahlat-Avrasya Bilim, Kültür ve Sanat Sempozyumu Bildiriler Kitabı (Editörler Doğru M. ve Aksoy E.), 46-59, 22-24 Eylül Ahlat- Bitlis 2014

[4] Akın M, Özvan A, Dinçer İ, Oyan V, Tapan M. Ahlat Taşı'nın atmosferik etkiler altındaki duyarlılığı, III. Uluslararası Ahlat-Avrasya Bilim, Kültür ve Sanat Sempozyumu Bildiriler Kitabı (Editörler Doğru M. ve Aksoy E.), 60-69, 22-24 Eylül Ahlat- Bitlis 2014.

[5] Kazancı N, Gürbüz A. Jeolojik Miras Nitelikli Türkiye Doğal Taşları, Türkiye Jeoloji Bülteni 2014. 57: 1.

[6] Pivko D. Natural stones in earth's history. Acta Geologica, 2003.58:73-86.

[7] Dinçer İ, Özvan A., Akın, M., Tapan, M., Oyan, V. İgnimbiritlerin kapiler su emme potansiyellerinin değerlendirilmesi: Ahlat Taşı örneği. Yüzüncü Yıl Üniversitesi Fen Bilimleri Enstitüsü Dergisi, 2012. 17 (2): 64-71

[8] Akıllı H. Taş eserlerin tahribatına neden olan etkenler, Rölöve ve Restorasyon Dergisi, 1987. 6:129-135,

[9] Gürdal E. Anıtlarda ve yapılarda kullanılmış doğal taşların bozulmaları ve korunmaları, Rölöve ve Restorasyon Dergisi 1982. 27-33.

[10] Vysniauskas V.V, Z1kas A.A. Determination of the thermal conductivity of ceramics by the Hot-Wire Technique. Heat Transfer Soviet Research, 1988. 20 (1): 137-142.

[11] Kaya A, Kar F. Properties of concrete containing waste expanded polystyrene and natural resin. Construction and Building Materials, 2016. 105: 572-578.

[12] Yap1 malzeme ve elemanları, özellikleri-kullanma yöntemleri, Ytong, İstanbul, 1985.

[13] Devecioğlu A.G. Gözenekli yapı taşlarında 1sı iletim parametrelerinin incelenmesi, Fırat Üniversitesi Fen Bilimleri Enstitüsü, Yüksek Lisans Tezi, 2001.

[14] Toksoy M. Endüstriyel malzemelerin 1sıl iletkenlik katsayıları, T.M.M.O. Mühendis ve Makine Dergisi 1988. 347: 1215 ,

[15] TS 699, Doğal yapı taşlarının muayene ve deney yöntemleri, TSE, Ankara, 1978. 